\title{
Potassium Channels and Neurovascular Coupling
}

\author{
Kathryn M. Dunn, PhD; Mark T. Nelson, PhD
}

\begin{abstract}
Neuronal activity is communicated to the cerebral vasculature so that adequate perfusion of brain tissue is maintained at all levels of neuronal metabolism. An increase in neuronal activity is accompanied by vasodilation and an increase in local cerebral blood flow. This process, known as neurovascular coupling (NVC) or functional hyperemia, is essential for cerebral homeostasis and survival. Neuronal activity is encoded in astrocytic $\mathrm{Ca}^{2+}$ signals that travel to astrocytic processes ('endfeet') encasing parenchymal arterioles within the brain. Astrocytic $\mathrm{Ca}^{2+}$ signals cause the release of vasoactive substances to cause relaxation, and in some circumstances contraction, of the smooth muscle cells (SMCs) of parenchymal arterioles to modulate local cerebral blood flow. Activation of potassium channels in the SMCs has been proposed to mediate NVC. Here, the current state of knowledge of NVC and potassium channels in parenchymal arterioles is reviewed. (Circ J 2010; 74: 608-616)
\end{abstract}

Key Words: Arterial smooth muscle; Astrocytes; Neurovascular coupling; Parenchymal arterioles; Potassium channels

$\mathbf{M}$ aintenance of cerebral homeostasis requires dynamic regulation of oxygen and glucose supply so as to match nutrient delivery to metabolic demand. ${ }^{1}$ This is achieved through extensive and precise regulation of blood flow within the brain. In the normally functioning brain, increases in neuronal activity are accompanied by rapid, spatially localized increases in blood flow that serve to avoid the development of ischemic conditions in active regions of the brain..$^{2-6}$ This coupling of increased neuronal activity to increased local cerebral blood flow (CBF), a process known as functional hyperemia or neurovascular coupling (NVC), occurs as a result of vasodilation at the level of the cerebral microcirculation and appears to depend on the generation of vasoactive substances. ${ }^{1}$ Abnormalities associated with cerebral microcirculatory function have been associated with a number of disorders, including Parkinson's disease, stroke, and migraine. ${ }^{7}$ In addition, chronically insufficient $\mathrm{CBF}$ is an end result of most risk factors associated with neurodegenerative diseases such as Alzheimer's disease and early onset dementia. ${ }^{8}$ Thus, elucidating the mechanisms by which neuronal activity regulates intracerebral arterioles is critical to the development of new targets and effective therapies for pathological conditions associated with cerebral microcirculatory dysfunction. Potassium $\left(\mathrm{K}^{+}\right)$channels play a central role in NVC and represent one such target for future therapeutics. The purpose of this review is to examine putative mechanisms of NVC and the role of $\mathrm{K}^{+}$channels in this process.

Blood flow to the brain is first conducted through a series of pial arteries on the surface of the brain, then through intracerebral arteries and arterioles within the brain tissue. Intracerebral (parenchymal) arterioles arise from branches of pial arteries that penetrate from the surface of the brain into the parenchyma (Figure 1). ${ }^{9}$ Parenchymal arterioles are structurally and functionally distinct from pial arteries. Within the cerebral cortex, these arterioles begin immediately distal to the Virchow-Robin space, are encased in astrocytic processes called 'endfeet', and terminate as an extensive capillary network. Parenchymal arterioles lack the extrinsic innervation of larger pial arteries, with primary regulation arising from astrocytes and neurons of central origin.,10,11

Recent evidence suggests that astrocytes play a significant role in the regulation of local CBF., $, 7,12-15$ An individual astrocyte has numerous processes that surround multiple synapses, and thus forms a tripartite synapse with pre-and post-synaptic neurons. ${ }^{16}$ Astrocytes also possess additional processes that target the cerebral microcirculation. These astrocytic processes terminate as perivascular endfeet that encase smooth muscle cells (SMCs) of parenchymal arterioles and capillaries (Figure 1).,212-15,17 This astrocytic architecture suggests that an individual astrocyte might be capable of integrating the activity of multiple neurons and translating this information into physiological signals, including those that regulate CBF by altering the vascular tone of parenchymal arterioles. Indeed, recent evidence points to a central role for astrocytes in functional hyperemia in the brain. Neurons themselves also release a number of important vasoactive substances, including nitric oxide, adenosine, and neurotransmitters; however, the potential role of these neuronal mediators in NVC is beyond the scope of the current review. 7,18

Astrocytes act as vital regulators of neuronal function, serving to modulate extracellular potassium $\left(\mathrm{K}^{+}\right)$concentration $\left(\left[\mathrm{K}^{+}\right]_{0}\right)$ and extracellular volume, and remove neurotransmitters from synapses. ${ }^{19-21}$ Astrocytes possess numerous receptors that could be activated by neurotransmitters..$^{22-24}$

Received February 23, 2010; accepted February 24, 2010; released online March 16, 2010

Department of Pharmacology, University of Vermont College of Medicine, Burlington, VT, USA

Mailing address: Mark T. Nelson, Department of Pharmacology, University of Vermont College of Medicine, 89 Beaumont Avenue,

Burlington, VT 05405, USA. E-mail: Mark.Nelson@uvm.edu

ISSN-1346-9843 doi:10.1253/circj.CJ-10-0174

All rights are reserved to the Japanese Circulation Society. For permissions, please e-mail: cj@j-circ.or.jp 


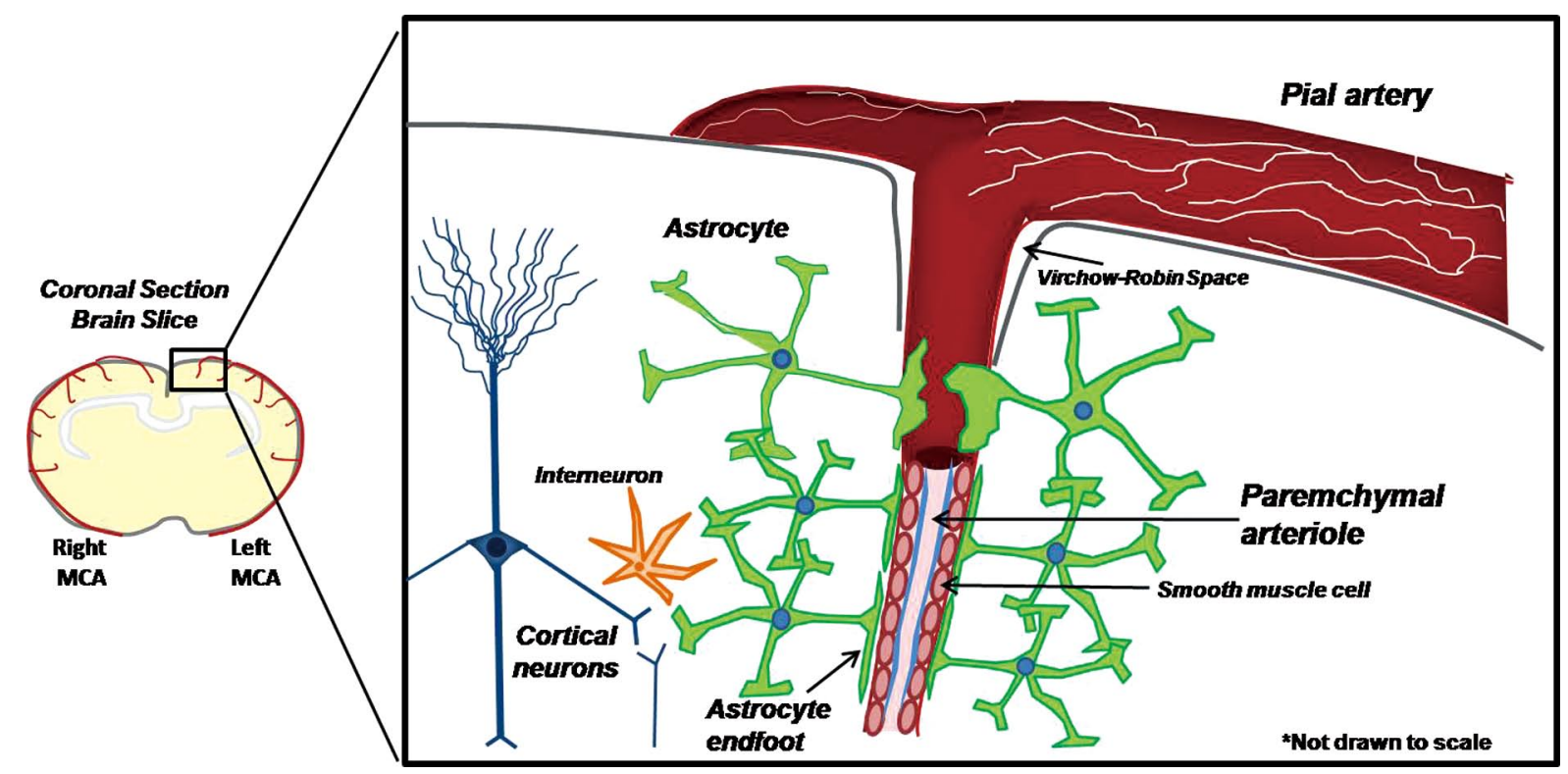

Figure 1. Pial arteries on the surface of the brain penetrate into the cortical parenchyma to give rise to parenchymal arterioles. Pial arteries are extrinsically innervated by sympathetic nerves (shown in white). As the arteriole penetrates into the brain parenchyma beyond the Virchow-Robin space, extrinsic innervation is lost and the arteriole becomes completely encased in astrocytic terminal processes called 'endfeet'. Astrocytes integrate information from neurons and other cell types (ie, interneurons) and translate that information into dynamic astrocytic $\mathrm{Ca}^{2+}$ signals that propagate to the endfoot and regulate parenchymal arteriolar tone in order to regulate local cerebral blood flow according to the metabolic needs of the surrounding tissue.

Activation of metabotropic glutamate receptors (mGluRs) located on astrocytic projections that surround synapses of glutamatergic neurons results in an increase in cytosolic calcium concentration $\left(\left[\mathrm{Ca}^{2+}\right]_{\mathrm{c}}\right)$ in the soma, which then propagates through astrocytic processes, ultimately resulting in a $\left[\mathrm{Ca}^{2+}\right]_{\mathrm{c}}$ increase in the endfoot (Figure 2). ${ }^{25,26}$ These $\left[\mathrm{Ca}^{2+}\right]_{\mathrm{c}}$ increases likely occur through activation of the phospholipase $\mathrm{C} /$ inositol trisphosphate $\left(\mathrm{InsP}_{3}\right)$ cascade, and involve release of endoplasmic reticulum $\mathrm{Ca}^{2+}$ through $\mathrm{InsP}_{3}$ receptors and possibly ryanodine receptors. ${ }^{26,27}$ Zonta et al elegantly showed that the dilation of cortical arterioles is dependent on astrocytic $\left[\mathrm{Ca}^{2+}\right]_{\mathrm{c}}$ increases induced by glutamate activation of mGluRs. ${ }^{14}$ Thus, the release of vasoactive substances from astrocytes in response to neuronal activation requires elevation of endfoot $\left[\mathrm{Ca}^{2+}\right]$, although the mechanisms underlying the generation of these signals and the nature of these mediators are poorly understood. ${ }^{12-14}$

\section{Astrocytic Signals and NVC}

Several signals based on arachidonic acid (AA) metabolism have been proposed to modulate vessel diameter in response to neuronal activity (Figure 2). ${ }^{12,14,28,29}$ Glutamate activation of astrocytic mGluRs leads to the $\mathrm{Ca}^{2+}$-dependent stimulation of phospholiase $\mathrm{A}_{2}\left(\mathrm{PLA}_{2}\right)$ and production of AA, which is metabolized to epoxyeicosatrienoic acid (EETs) by the action of cytochrome P450 (CYP) epoxygenases, with 11,12EET and 14,15-EET being major vasoactive components. ${ }^{30-32}$ EETs, which are potent vasodilators, have recently been implicated in suppressing vasomotion and maintaining vasodilation of cortical arterioles following astrocytic AMPA receptor stimulation. ${ }^{30,33-35}$

Based on the effects of cyclooxygenase (COX) inhibitors in neonatal brain slices, Zonta et al suggested that elevation of astrocytic $\left[\mathrm{Ca}^{2+}\right]$ c following glutamate activation of mGluRs leads to the generation of a COX product that activates receptors on vascular SMCs to generate vasodilation. ${ }^{14}$ Consistent with the speculation that this COX product is $\mathrm{PGE}_{2}$, Zonta and colleagues demonstrated that cultured astrocytes produce $\mathrm{PGE}_{2}$ in a pulsatile manner and $\mathrm{PGE}_{2}$ $(20 \mu \mathrm{mol} / \mathrm{L})$ dilates arterioles in brain slices. ${ }^{14,36}$ Importantly, the vasodilatory responses observed in these studies exhibited a significant delay (1-3 min) following neuronal activation by electrical field stimulation (EFS), activation of astrocytic mGluRs (t-ACPD [ $\{ \pm\}$-1-aminocyclopentane-trans-1,3-dicarboxylic acid]), patch seal-evoked stimulation, or by $\mathrm{PGE}_{2}$ application. This delayed response is a phenomenon that is not observed in vivo in adult animals. The slow response in brain slices might reflect the use of neonatal animals in which the neurons and vasculature are not fully developed. Alternatively, the time course of PGE2 action itself might be slow, which might suggest that this pathway does not mediate the rapid coupling of neuronal activity to vascular dilation but contributes instead to the regulation of blood flow on a longer time scale. Additionally, the observation that COX inhibition only partially suppresses vasodilation is consistent with the view that multiple mechanisms contribute to the neuronal regulation of arteriolar diameter.

In addition to inducing vasodilation, astrocyte-derived AA has been implicated in generating vasoconstriction. Mulligan and MacVicar have proposed that a rise in astrocytic endfoot $\left[\mathrm{Ca}^{2+}\right]$ stimulates PLA2, which produces AA that then diffuses to the parenchymal arteriolar SMCs, where it is converted to 20-HETE by CYP $\omega$-hydroxylase. ${ }^{12}$ The suggestion is that 20-HETE constricts arterioles by inhibiting SMC large-conductance calcium-sensitive $\mathrm{K}^{+}(\mathrm{BK})$ channels, 


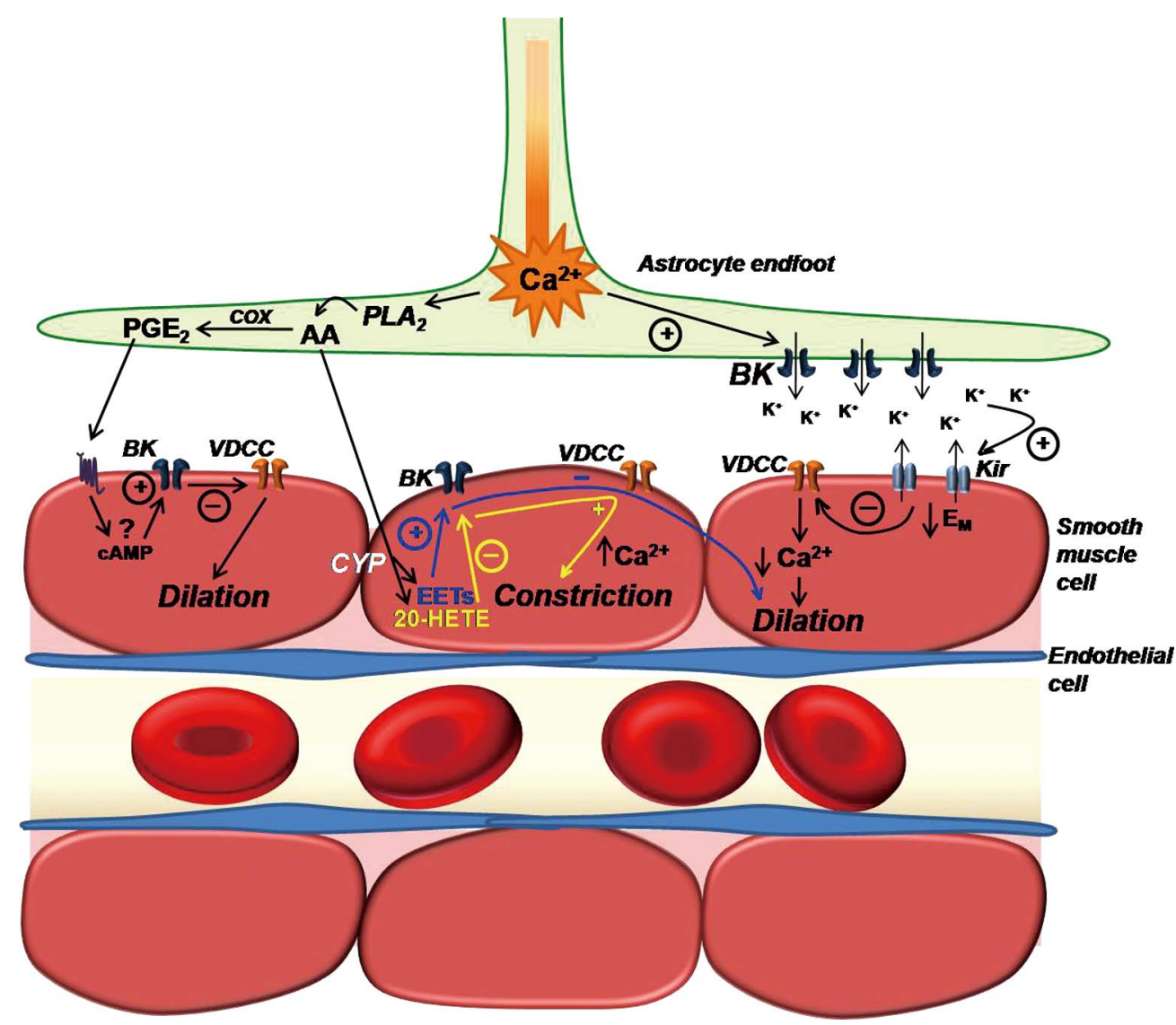

Figure 2. Illustration depicting the involvement of parenchymal arteriolar smooth muscle cell (SMC) $\mathrm{K}^{+}$channels in putative mechanisms of neurovascular coupling. Neuronal activity stimulates astrocytic metabotropic glutamate receptors (not shown) to produce a propagating rise in $\left[\mathrm{Ca}^{2+}\right]_{i}$ that terminates in perivascular endfeet. Increased astrocytic endfoot $\left[\mathrm{Ca}^{2+}\right]$ activates $\mathrm{BK}$ channels to release $\mathrm{K}^{+}$into the perivascular cleft. Moderate elevations in [ $\left.\mathrm{K}^{+}\right]_{0}$ in the perivascular cleft activate Kir channels in parenchymal arteriole SMCs, resulting in SMC membrane potential hyperpolarization, decreased $\mathrm{Ca}^{2+}$ entry through VDCCs, decreased $\left[\mathrm{Ca}^{2+}\right] \mathrm{i}$, and vasodilation. Increased astrocytic endfoot $\left[\mathrm{Ca}^{2+}\right]$ also activates the $\mathrm{Ca}^{2+}$ sensitive enzyme cytosolic phoshpolipase A2 (PLA2). PLA2 hydrolyzes membrane phospholipids to release the fatty acid arachidonic acid (AA). AA is then metabolized by cyclooxygenase (COX) and prostaglandin synthases to yield PGE2, or is believed to diffuse to the parenchymal arteriole SMC, where it is metabolized by cytochrome P-450 enzymes to generate EETs and/or 20-HETE. The mechanism of action of PGE2 on parenchymal arteriole SMCs is unknown, but based on studies done in pial arteries, it might involve cAMP-dependent activation of SMC BK channels, and subsequent SMC hyperpolarization and vasodilation. EETs formed in arteriolar SMCs by the metabolism of astrocytederived AA are proposed to activate SMC BK channels to elicit membrane hyperpolarization and vasodilation. Conversely, 20-HETE is believed to inhibit parenchymal arteriolar SMC BK channels resulting in membrane depolarization, activation of VDCCs, elevation of $\left[\mathrm{Ca}^{2+}\right]_{\mathrm{i}}$, and vasoconstriction.

an inference based on the inhibitory effects of the PLA2 inhibitor MAFP $(100 \mu \mathrm{mol} / \mathrm{L})$ and the 20-HETE synthesisinhibitor HET0016 $(100 \mu \mathrm{mol} / \mathrm{L})$ on the observed constriction. However, these experiments examined non-preconstricted arterioles in brain slices, and the contribution of BK channels is expected to be negligible in the absence of tone. ${ }^{37}$ Accordingly, it is difficult to reconcile the observed constrictor effect of 20-HETE with a mechanism involving inhibition of vascular SMC BK channels. In addition, these observations must be interpreted with caution as the concentration of HET0016 used was very high $(100 \mu \mathrm{mol} / \mathrm{L})$, and likely to non-selectively inhibit the formation of other AA metabolites that might be involved in NVC. In human renal microsomes, the IC50 of HET0016 on CYP epoxygenase and COX activities is $2.8 \mu \mathrm{mol} / \mathrm{L}$ and $2.3 \mu \mathrm{mol} / \mathrm{L}$, respectively. ${ }^{38}$ Also, $1 \mu \mathrm{mol} / \mathrm{L}$ HET0016 is sufficient to block 20-HETE pro- duction in intact cerebral arteries by $90 \% .{ }^{39}$ Thus, the actual role of 20-HETE in NVC and its direct functional effects on parenchymal arterioles remains uncertain.

One astrocytic signal that clearly has the potential to generate both vasodilation and vasoconstriction is $\mathrm{K}^{+} .{ }^{40}$ The regulation of $\left[\mathrm{K}^{+}\right]_{\mathrm{o}}$ by astrocytes has been extensively studied in the retina, where astrocytes are suggested to function as a $\mathrm{K}^{+}$siphon, taking up $\mathrm{K}^{+}$from regions of high concentration (perisynaptic regions) and releasing $\mathrm{K}^{+}$to regions of lower extracellular concentration (perivascular regions). ${ }^{21}$ Consistent with this $\mathrm{K}^{+}$buffering role, astrocytes display a large $\mathrm{K}^{+}$ conductance; a hyperpolarized $V_{\mathrm{m}}$ (approximately $-80 \mathrm{mV}$ ) that is positive to the $\mathrm{K}^{+}$equilibrium potential, $E_{\mathrm{K}}(-102 \mathrm{mV})$; and exhibit polarized expression of $\mathrm{K}^{+}$channels. ${ }^{41,42}$ Specifically, BK channels are abundantly expressed in perivascular endfeet. ${ }^{43}$ In brain slices, neuronal stimulation by EFS pro- 
duces $\mathrm{Ca}^{2+}$-sensitive $\mathrm{K}^{+}$(BK channel) currents in astrocytic endfeet that are activated by the rise in endfoot $\left[\mathrm{Ca}^{2+}\right]$ and result in vasodilation. ${ }^{44}$ Activation of endfoot $\mathrm{BK}$ channels releases $\mathrm{K}^{+}$into the perivascular space, producing a localized elevation in $\left[\mathrm{K}^{+}\right]_{0}$ in the spatially restricted microenvironment between the endfoot and the arteriole that is sensed by the arteriolar smooth muscle. By altering the $\left[\mathrm{K}^{+}\right]_{\mathrm{o}}$ in the perivascular space through endfoot BK channel-mediated $\mathrm{K}^{+}$release, the astrocyte can generate a signal that is capable of producing vasodilation or vasoconstriction. Strong evidence indicates that the vasodilatory response to $\mathrm{K}^{+}$ released from the endfoot is mediated by inward-rectifier $\mathrm{K}^{+}$ (Kir) channels in parenchymal arteriole smooth muscle. Barium, a selective inhibitor of $\mathrm{K}_{\text {ir }}$ channels (at concentrations $<100 \mu \mathrm{mol} / \mathrm{L}$ ), blocks vasodilation elicited by neuronal stimulation with EFS in brain slices, but does not affect the increase in $\left[\mathrm{Ca}^{2+}\right]_{\mathrm{c}}$ in astrocytic endfeet. ${ }^{44}$

\section{K+ Channels in the Control of Parenchymal Arteriolar Tone}

The membrane potential of arterial SMCs is a key determinant of vascular tone and is regulated by $\mathrm{K}^{+}$channels. Opening of $\mathrm{K}^{+}$channels in vascular SMC membranes allows $\mathrm{K}^{+}$to flow out of the cell, resulting in membrane hyperpolarization, whereas inhibition of $\mathrm{K}^{+}$channels results in membrane depolarization. $\mathrm{K}^{+}$channel-mediated membrane hyperpolarization closes voltage-dependent $\mathrm{Ca}^{2+}$ channels (VDCCs), which decreases $\mathrm{Ca}^{2+}$ entry and leads to vasodilation. ${ }^{45,46}$ VDCCs are very sensitive to membrane potential, such that modest fluctuations in membrane potential can dramatically change $\mathrm{Ca}^{2+}$ entry. ${ }^{47}$ Consequently, minor changes in membrane potential can have a significant effect on arterial diameter. ${ }^{48}$ The membrane potential of SMCs in parenchymal arterioles pressurized to physiological levels $(40 \mathrm{mmHg})$ is approximately $-45 \mathrm{mV}$, and the arterioles are about $30 \%$ constricted. ${ }^{44}$ In cerebrospinal fluid, $E_{\mathrm{K}}$ is about $-102 \mathrm{mV}$. Membrane potential hyperpolarization to $-60 \mathrm{mV}$ causes a maximum dilation of cerebral arteries, and depolarization to approximately $-30 \mathrm{mV}$ causes maximal constriction. ${ }^{48}$ Therefore, even modest activation of SMC $\mathrm{K}^{+}$channels can cause significant vasodilation.

The 4 different subtypes of $\mathrm{K}^{+}$channels identified in arterial SMCs are inward rectifier $\mathrm{K}^{+}\left(\mathrm{K}_{\text {ir }}\right)$ channels, $\mathrm{Ca}^{2+}$-sensitive $\mathrm{K}^{+}\left(\mathrm{K}_{\mathrm{Ca}}\right)$ channels, voltage-dependent $\mathrm{K}^{+}\left(\mathrm{K}_{\mathrm{v}}\right)$ channels, and ATP-sensitive $\mathrm{K}^{+}$(KATP) channels. ${ }^{49}$ The expression profile and functional contribution of each subtype can vary according to tissue bed and caliber of the arterial segment. ${ }^{50}$ There is functional evidence for all $4 \mathrm{~K}^{+}$channel subtypes in SMCs of parenchymal arterioles, but their relative roles have not been as well characterized as in pial artery SMCs. ${ }^{51-54}$

\section{Kir Channels}

A number of arteries, including cerebral and coronary arteries, dilate to a modest elevation in extracellular $\mathrm{K}^{+}$. $\mathrm{K}^{+}$-induced dilations are caused by activation of strong inward rectifier $\mathrm{K}^{+}$channels in the SMCs. ${ }^{49}$ In pial arteries, disruption of the gene for the strong inward rectifier $\mathrm{K}^{+}$channel, $\mathrm{K}_{\mathrm{ir}} 2.1$, abolished $\mathrm{K}^{+}$-induced dilations. ${ }^{55,56}$ The property of inward rectification is likely conferred to $\mathrm{K}_{\text {ir }}$ channels through the drawing out of positively charged polyamines plugging the inside of the pore by membrane potential hyperpolarization. ${ }^{57-59}$ The midpoint-of the-activation curve for $\mathrm{K}_{\text {ir }}$ channels corresponds to $\mathrm{EK}_{\mathrm{K}}$, such that elevation of external $\mathrm{K}^{+}$shifts the activation curve to more positive potentials. ${ }^{60}$ The only exper- imentally useful blocker of $\mathrm{K}_{\text {ir }}$ channels is external barium, which blocks the pore in a voltage-dependent manner with an apparent half block constant of $10 \mu \mathrm{mol} / \mathrm{L}$ at $-40 \mathrm{Mv} .{ }^{61} \mathrm{At}$ concentrations below $100 \mu \mathrm{mol} / \mathrm{L}$, barium ions do not cause significant block of smooth muscle Kv, BK, or KATP channels. ${ }^{62}$ There are no selective activators of $K_{\text {ir }}$ channels, except external $\mathrm{K}^{+}$and membrane potential hyperpolarization.

The activity of $\mathrm{K}_{\mathrm{ir}}$ channels in arteriolar myocytes is highly dependent on membrane potential and $\left[\mathrm{K}^{+}\right]_{\mathrm{o}}$. In parenchymal arteriolar SMCs, where the density of barium-sensitive $\mathrm{K}_{\text {ir }}$ currents is greater than that observed in pial artery myocytes, elevation of $\left[\mathrm{K}^{+}\right]_{\mathrm{o}}$ shifts the $\mathrm{K}_{\text {ir }}$ activation curve to more positive potentials, and an increase in $\left[\mathrm{K}^{+}\right]_{\mathrm{o}}$ from $3 \mathrm{mmol} / \mathrm{L}$ to $10 \mathrm{mmol} / \mathrm{L}$ increases the $\mathrm{K}_{\text {ir }}$ current density 6.3 fold. ${ }^{44}$ The increase in $\mathrm{K}$ ir current density with elevated $\left[\mathrm{K}^{+}\right]_{\mathrm{o}}$ is associated with suppression of $\mathrm{SMC} \mathrm{Ca}{ }^{2+}$ oscillations and vasodilation. Increasing $\left[\mathrm{K}^{+}\right]_{\mathrm{o}}$ activates $\mathrm{K}_{\mathrm{ir}}$, resulting in membrane potential hyperpolarization and vasodilation only up to a concentration of $\sim 20 \mathrm{mmol} / \mathrm{L}-$ the $\left[\mathrm{K}^{+}\right]_{\mathrm{o}}$ at which $\mathrm{EK}_{\mathrm{K}}$ is similar to the SMC resting membrane potential. Further increases in $\left[\mathrm{K}^{+}\right]_{0}$ depolarize the arteriolar SMC membrane potential and cause vasoconstriction. Treatment with barium prevents the dilation of parenchymal arterioles to modest elevations in $\left[\mathrm{K}^{+}\right]_{\mathrm{o}}$, but does not affect the constriction to greater than $20 \mathrm{mmol} / \mathrm{L}\left[\mathrm{K}^{+}\right]_{\mathrm{o}}$, indicating that $\mathrm{K}_{\text {ir }}$ mediates $\mathrm{K}^{+}$-induced dilation but not $\mathrm{K}^{+}$-induced constriction in parenchymal arterioles. Exposure of parenchymal arterioles to barium alone does not affect vascular diameter, suggesting that SMC Kir channels are not tonically active and contribute minimally to tone in these vessels.

\section{BK Channels}

BK channels have been identified in virtually every type of smooth muscle. The characteristic smooth muscle BK channel complex is composed of an $\alpha$ pore-forming subunit and an auxillary $\beta 1$ subunit. ${ }^{63-65}$ The $\beta 1$ subunit acts to increase the apparent voltage- and $\mathrm{Ca}^{2+}$-sensitivity of the channel. Targeted disruption of the $\beta 1$ subunit gene leads to hypertension and left ventricular hypertrophy. ${ }^{66}$ A number of recent animal studies have shown that the $\beta 1$ subunit, and hence BK channel function, is downregulated in hypertension and diabetes. ${ }^{67-71}$ Two polymorphisms of the BK channel $\beta 1$ subunit-KCNMB1-E65K and KCNMB1-V110L - are common in multiple ethnic and racial groups; an additional polymorphism (R140W) is found in individuals of African descent. The first non-synonymous coding polymorphism was described by Fernandez-Fernandez et al, who identified the E65K polymorphism by direct sequence analysis of the 4 Kcnmbl exons in a Spanish cohort. ${ }^{72}$ Heterologous expression studies in HEK293 cells established that the E65K polymorphism was a gain-of-function variant that increased BK-channel sensitivity to activation by $\mathrm{Ca}^{2+}$. Genetic association studies in the Spanish cohort demonstrated that carriers of E65K, which was present in $21 \%$ of the population examined, were less likely to have diastolic hypertension. ${ }^{72}$ In follow-up studies, the association of E65K with blood pressure appeared to be strongest among post-menopausal women. ${ }^{73}$

BK channels are selectively blocked by the scorpion toxins iberiotoxin and charybdotoxin, as well as the alkaloid paxilline. ${ }^{74-76}$ There are a number of synthetic openers of BK channels. ${ }^{77-79}$ However, the majority of these openers lack selectivity in intact tissues, and therefore their usefulness has been limited. An exception is NS11021, which has recently been shown to decrease smooth muscle excitability through activation of BK channels. ${ }^{80} \mathrm{BK}$ channels are directly and 
indirectly activated by vasodilators that elevate cGMP and cAMP concentration. ${ }^{49,81,82} \mathrm{BK}$ channels have also been shown to be modulated by AA metabolites. BK channel activity is inhibited by 20-HETE through protein kinase C (PKC) activation and increased by EETs. ${ }^{83-87}$

BK currents have been identified in parenchymal arteriolar SMCs; however, these currents have been suggested to be quite small in the physiologically relevant voltage range of -50 to $-10 \mathrm{mV} .{ }^{88}$ In addition, whereas treatment of pressurized pial arteries with BK channel inhibitors causes pronounced vasoconstriction, parenchymal arteriolar tone does not appear to be substantially affected by BK channel inhibition, as BK channel block by subdural superfusion of paxilline $(1 \mu \mathrm{mol} / \mathrm{L})$ does not significantly affect resting cortical CBF in vivo. ${ }^{51}$ These observations suggest that, unlike pial arteries, where BK channels appear to play a major role in regulating tone, the functional significance of $\mathrm{BK}$ channel activity in parenchymal arterioles might not be substantial. ${ }^{37}$ Reduced BK channel-mediated opposition of myogenic tone could potentially explain the greater relative tone observed in parenchymal arterioles compared to pial arteries. ${ }^{89}$ The mechanism and physiological significance of diminished basal BK channel activity in pressurized parenchymal arterioles compared to pial arteries is unclear. However, BK channels in parenchymal arteriolar SMCs are involved in modulating vascular diameter in response to vasoactive chemical stimuli. For example, parenchymal arteriolar dilation to glutamate in newborn piglets is mediated by activation of SMC BK channels. ${ }^{90}$

\section{Voltage-Dependent Potassium (Kv) Channels}

$\mathrm{Kv}$ channels are present in all types of vascular smooth muscle, and serve to oppose depolarizing, contractile influences by virtue of their voltage-dependence. ${ }^{49}$ In vascular smooth muscle, the consensus is that these channels are composed of heteromers of $\mathrm{Kv} 1.2 / 1.5 .{ }^{91,92} \mathrm{Kv}$ channels can be inhibited by vasoconstrictors through PKC activation. ${ }^{93-95}$ Recent evidence indicates modest elevations of glucose can also inhibit $\mathrm{Kv}$ channels through activation of PKC. ${ }^{53,96}$ The 4-aminopyridine (4-AP) is a potent inhibitor of these channels. ${ }^{62}$ Selective openers of these channels have not been identified. As in pial arteries, $\mathrm{Kv}$ channels play a significant role in determining the level of myogenic tone in pressurized parenchymal arterioles. Kv channel currents activated by membrane depolarization are observed in parenchymal arteriolar SMCs. ${ }^{53}$ The biophysical properties of these currents along with reverse transcription-polymerase chain reaction results indicate that $\mathrm{Kv}$ channels in parenchymal arterioles are heterotetrameric channels composed of Kv1.2 and Kv1.5 subtypes. This is the same type of $\mathrm{Kv}$ channel assembly present in pial artery SMCs. Kv current in isolated parenchymal arteriolar SMCs is significantly reduced by application of 4-AP, which also constricts pressurized arterioles and arterioles in brain slices by roughly $40 \%$. Hence, at physiological intravascular pressures $\mathrm{Kv}$ channels actively oppose myogenic constriction in parenchymal arterioles. There is some evidence that $\mathrm{Kv}$ channels also mediate changes in membrane potential and vascular tone in parenchymal arterioles in response to vasoactive agents, although this has not been well studied. However, elevated extracellular glucose concentration diminishes $\mathrm{Kv}$ current in arteriolar SMCs and promotes vasoconstriction of parenchymal arterioles through activation of PKC. ${ }^{53}$

\section{Katp Channels}

KATP channels have been identified in a wide variety of smooth muscle types, and are likely an octomer of 4 sulfonylurea receptors (SUR2B) and 4 inward rectifier (Kir6.1) subunits. ${ }^{60,97}$ KATP channels lack voltage-dependence, and exhibit very weak inward rectification. They are also inhibited by intracellular ATP, and may open when ATP/ADP ratio changes during hypoxic or ischemic conditions. ${ }^{60}$ Under physiological conditions, SMC KATP channels are potently activated by vasodilators that activate cAMP-dependent protein kinase and are inhibited by vasoconstrictors that activate PKC. ${ }^{49,60}$ KATP channels in vascular smooth muscle are potently inhibited by sulfonylurea and hypoglycemic drugs, such as glibenclamide, and are selectively activated by a wide variety of synthetic compounds, such as pinacidil and cromakalim. ${ }^{60,98}$ There is no direct electrophysiological evidence for KATP channels in SMCs of parenchymal arterioles. However, preconstricted parenchymal arterioles dilate in response to levcromakalim, a KATP channel agonist. ${ }^{54}$ Additionally, dilation of parenchymal arterioles to mild hypercapnia is blocked by glibenclamide $(5 \mu \mathrm{mol} / \mathrm{L})$, a selective inhibitor of KATP channels. ${ }^{99}$ It has also been reported that KATP channel activation mediates parenchymal arteriolar membrane hyperpolarization in response to basic fibroblast growth factor. ${ }^{100}$ Glibenclamide-sensitive KATP currents measured in pial artery SMCs are activated by synthetic vasodilators such as pinacidil, as well as by endogenous vasodilators such as calcitonin gene-related peptide and VIP. ${ }^{101,102}$ While there is evidence that supports the presence of KATP channels in parenchymal arteriolar SMCs, the biophysical properties of KATP channels in these vessels are not known, and the functional role of KАTP channels in regulating parenchymal arteriolar tone requires further characterization.

\section{Parenchymal Arteriolar Smooth Muscle K+ Channels and NVC}

Multiple parallel pathways are activated by the increase in $\left[\mathrm{Ca}^{2+}\right]_{\mathrm{c}}$ in astrocytes in response to neuronal activation. This is evidenced by the fact that pharmacological inhibition or genetic manipulation of any of the putative mediators of NVC never fully blocks the vascular response. Also, a rise in astrocytic endfoot $\left[\mathrm{Ca}^{2+}\right]_{c}$ potentially activates a wide range of $\mathrm{Ca}^{2+}$-sensitive proteins. These $\mathrm{Ca}^{2+}$-sensitive proteins include $\mathrm{BK}$ channels, which release $\mathrm{K}^{+}$ions as a vasoactive signal, as well as PLA2, which provides the substrate (AA) for the generation of eicosanoid and prostanoid vasoactive mediators. Because functional hyperemia in the brain is a prerequisite for survival, it is not surprising that redundant mechanisms have evolved to maintain it. However, redundant parallel mechanisms that ensure functional NVC might ultimately converge on parenchymal arteriolar $\mathrm{SMC} \mathrm{K}^{+}$channels to elicit their vascular response.

\section{Vasodilation in Response to Neuronal Activity}

Activation of parenchymal arteriolar smooth muscle $\mathrm{K}^{+}$ channels during NVC would cause vasodilation and thereby increase local $\mathrm{CBF}$. Here, we consider evidence that putative astrocytic mediators of NVC-external $\mathrm{K}^{+}, \mathrm{PGE}_{2}$, and EETsdilate parenchymal arterioles through activation of smooth muscle $\mathrm{K}^{+}$channels.

\section{External $\mathbf{K}^{+}$}

As noted above, isolated SMCs from parenchymal arterioles 
have a relatively high density of strong inward rectifier $\mathrm{K}^{+}$ channels that are activated by external $\mathrm{K}^{+}$and membrane hyperpolarization, consistent with the properties of $\mathrm{K}_{\mathrm{ir}} 2 \mathrm{fam}-$ ily members. Elevation of $\left[\mathrm{K}^{+}\right]_{\mathrm{o}}$ from $3 \mathrm{mmol} / \mathrm{L}$ to $8 \mathrm{mmol} / \mathrm{L}$ hyperpolarizes parenchymal arteriolar membranes from -45 to $-80 \mathrm{mV}$, and causes a rapid and profound dilation of isolated pressurized parenchymal arterioles as well as arterioles in brain slices. ${ }^{44}$ These effects are blocked by low concentrations of barium ions, which also block NVC responses to neuronal stimulation or $\mathrm{Ca}^{2+}$ uncaging in astrocytic endfeet in brain slices (by approximately 70\%) and reduce hyperemic responses to whisker stimulation in vivo (by about 50\%). Taken together, these results provide compelling evidence that parenchymal arterioles can dilate to external $\mathrm{K}^{+}$through activation of $\mathrm{K}_{\text {ir }}$ channels.

\section{PGE2}

Based on the effects of COX inhibitors, several groups have proposed that $\mathrm{PGE}_{2}$ released from astrocytic processes is responsible for NVC. ${ }^{14,103-105} \mathrm{PGE}_{2}(20 \mu \mathrm{mol} / \mathrm{L})$ has been shown to dilate arterioles in brain slices from neonatal rats. ${ }^{14}$ $\mathrm{PGE}_{2}$ might act through EP2 or EP4 prostanoid receptors in SMCs to elevate cAMP, which could lead to vasodilation by activating BK channels or KATP channels. This type of $\mathrm{K}^{+}$ channel-dependent mechanism of $\mathrm{PGE}_{2}$ dilation has been documented in renal arteries but has not been explored in parenchymal arterioles. ${ }^{106} \mathrm{PGE}_{2}$ dilates pial arteries from cat and rat, and reportedly dilates human middle cerebral arteries through EP4 receptor activation. ${ }^{107,108}$ However, there is limited direct evidence of $\mathrm{PGE}_{2}$-mediated dilation in parenchymal arterioles. COX inhibition with indomethacin dilates pressurized parenchymal arterioles by $15 \%$, but the mechanism of this effect is not known. ${ }^{109}$ We have observed that in pressurized mesenteric arteries, $\mathrm{PGE}_{2}$ only dilates the vessel in the presence of functional nitric oxide synthase, suggesting an endothelial effect rather than a SMC effect (unpublished observations). $\mathrm{PGE}_{2}$ has also been reported to elicit vasoconstriction in a variety of arterial segments, including cerebral arteries. ${ }^{110-112}$ The direct effect of PGE 2 on parenchymal arteriolar tone and its mechanism of action requires further investigation.

\section{EETs}

The release of EETs has been proposed to be involved in NVC. ${ }^{113-116}$ Subdural superfusion of epoxygenase inhibitors reportedly reduces functional hyperemia in the rat somatosensory cortex by 28-69\%.115 EETs hyperpolarize cerebral artery SM membrane potential and potently dilate pial arteries through direct activation of SM BK channels and through indirect activation of SM BK channels by increasing $\mathrm{Ca}^{2+}$ sparks. ${ }^{33,117-121}$ EET-mediated functional hyperemia in the brain very likely occurs through activation of $\mathrm{K}^{+}$channels in parenchymal arteriolar SMCs. However, the direct effect of EETs on $\mathrm{K}^{+}$channel activity, SMC membrane potential, and parenchymal arteriolar tone has not been investigated.

\section{Vasoconstriction in Response to Neuronal Activity}

Several groups have observed vasoconstriction of parenchymal arterioles in response to neuronal activation or $\mathrm{Ca}^{2+}$ uncaging in astrocytic endfeet. ${ }^{12,51,113}$ The function of vasoconstriction in NVC is unknown, and this phenomenon might be more pathological than physiological. Inhibition of parenchymal arteriolar smooth muscle $\mathrm{K}^{+}$channels would depo- larize the membrane and cause vasoconstriction, and there is evidence that the primary putative vasoconstrictor mediator of NVC, 20-HETE, acts through this mechanism.

As discussed above, inhibition of 20-HETE formation prevents vasoconstriction of parenchymal arterioles in response to neuronal stimulation in brain slices. ${ }^{12}$ The 20-HETE inhibition also prevents light-evoked vasoconstrictions in mammalian retina. ${ }^{113}$ This evidence suggests that 20-HETE constricts parenchymal arteriolar SMCs. Direct evidence in parenchymal arterioles is lacking, but 20-HETE potently constricts pial arteries. ${ }^{122-124}$ The 20-HETE constricts arteries by inhibiting SMC BK channels through PKC. ${ }^{84,85}$ The physiological significance of this mechanism is unclear, not only because of the questionable function of neuronal activity-induced vasoconstriction, but also because basal BK channel activity in parenchymal arteriole SMCs might be quite low. BK channel blockers have little effect on the diameter of arterioles in brain slices and on resting cortical CBF. ${ }^{51}$

External $\mathrm{K}^{+}$can produce parenchymal arteriolar constriction in addition to dilation. While modest elevation of $\left[\mathrm{K}^{+}\right]_{\mathrm{o}}$ dilates parenchymal arterioles through activation of $\mathrm{K}_{\mathrm{ir}}$, elevation of $\left[\mathrm{K}^{+}\right]_{\mathrm{o}}$ above $20 \mathrm{mmol} / \mathrm{L}$ evokes constriction through SMC membrane potential depolarization. ${ }^{51,125}$ In brain slices, raising $\left[\mathrm{K}^{+}\right]_{\mathrm{o}}$ in the bath also converts evoked parenchymal arteriolar dilations with neuronal stimulation or endfoot $\mathrm{Ca}^{2+}$ uncaging into constrictions. ${ }^{51}$ In NVC, the astrocyte can tune the polarity of the arteriolar diameter response by altering the magnitude of $\mathrm{K}^{+}$release from the endfoot.

$\mathrm{PGE}_{2}$ also has the potential to mediate neuronal activityinduced constriction. Human pial artery dilation in response to PGE2 occurs through EP4 receptors. ${ }^{108}$ In some types of cerebral arteries, $\mathrm{PGE}_{2}$ has been shown to cause constricton through EP1 or EP3 receptors. ${ }^{112}$ The specificity of the cerebral vascular response to $\mathrm{PGE}_{2}$ (dilation vs constriction) appears to be conferred by the prostanoid receptors stimulated. Which prostanoid receptor subtypes are expressed and their relative expression in SMCs of parenchymal arterioles is not known. Also, as stated above, the direct effect of $\mathrm{PGE}_{2}$ on parenchymal arterioles has not been studied.

In studies observing vasoconstriction with a rise in astrocytic endfoot $\mathrm{Ca}^{2+}$ or neuronal activation, a 20-HETE inhibitor, albeit at a high concentration, largely abolished the constrictor response. However, if there is a role for astrocytemediated vasoconstriction in normal physiology or in pathology, external $\mathrm{K}^{+}, \mathrm{PGE}_{2}$, and 20 -HETE could potentially be mediators.

\section{Indirect Role of Parenchymal Arteriolar SMC $\mathrm{K}+$ Channels in NVC}

Smooth muscle $\mathrm{K}^{+}$channels also indirectly influence NVC by setting the resting level of tone in parenchymal arterioles prior to neuronal activation. In pial arterioles, the pre-existing level of tone in the vessel determines the magnitude and polarity (constriction vs vasodilation) of the vascular response to vasoactive substances. ${ }^{126,127}$ Similarly, the response of parenchymal arterioles to putative signals involved in NVC is dictated by the resting tone of the vessel. ${ }^{128}$ Varying the degree of preconstriction of parenchymal arterioles in brain slices with increasing concentrations of the thromboxane receptor agonist $\mathrm{U}-46619$ alters the response of the arteriole to $\mathrm{K}^{+}$such that the greater the initial level of preconstriction, the greater the magnitude of the vasodilator response to $10 \mathrm{mmol} / \mathrm{L}\left[\mathrm{K}^{+}\right]_{\mathrm{o}}$. Stimulation of mGluR to elicit a rise in astrocytic $\left[\mathrm{Ca}^{2+}\right]_{\mathrm{c}}$ evokes constriction in modestly preconstricted arterioles 
(70-100\% of baseline) and dilation in arterioles with greater initial tone. The switch in polarity of vascular response appears to occur at a level of tone corresponding to approximately $50-70 \%$ of baseline diameter.

As key regulators of membrane potential, and therefore $\mathrm{Ca}^{2+}$ influx through VDCCs, SMC $\mathrm{K}^{+}$channels are primary determinants of parenchymal arteriolar tone. Therefore, arteriolar $\mathrm{SMC} \mathrm{K}^{+}$channels likely play a role in determining the magnitude and polarity of the vascular response to neuronal activation by setting the initial level of tone of the arteriole.

\section{Concluding Remarks}

Precise regulation of $\mathrm{CBF}$ is essential for homeostasis in the brain. Smooth muscle $\mathrm{K}^{+}$channels are critical regulators of vascular tone and blood flow in cerebral arteries and arterioles. Many mechanisms of chemical, mechanical, and humoral regulation of $\mathrm{CBF}$ involve modulation of $\mathrm{SMC} \mathrm{\textrm {K } ^ { + }}$ channel activity. Parenchymal arteriolar SMC $\mathrm{K}^{+}$channels are important in the process of NVC and functional hyperemia in the brain, and have potential as therapeutic targets in pathological conditions in which NVC is compromised, including Alzheimer's disease, dementia, diabetes, and hypertension.

\section{Acknowledgements}

We thank Dr David Hill-Eubanks for comments on the manuscript. This work was supported by NIH grants DK053832, DK065947, HL44455, HL098243, HL077378, T32HL007944/6-10, and the Totman Trust for Medical Research.

\section{References}

1. Roy CS, Sherrington CS. On the regulation of the blood-supply of the brain. J Physiol 1890; 11: 85-158.

2. Anderson CM, Nedergaard M. Astrocyte-mediated control of cerebral microcirculation. Trends Neurosci 2003; 26: 340-344; author reply 344-345.

3. Iadecola C. Regulation of the cerebral microcirculation during neural activity: Is nitric oxide the missing link? Trends Neurosci 1993; 16: 206-214.

4. Laughlin SB, Sejnowski TJ. Communication in neuronal networks. Science 2003; 301: 1870-1874.

5. Chaigneau E, Oheim M, Audinat E, Charpak S. Two-photon imaging of capillary blood flow in olfactory bulb glomeruli. Proc Natl Acad Sci USA 2003; 100: 13081-13086.

6. Fujikawa T, Tochikubo O, Kura N, Kiyokura T, Shimada J, Umemura S. Measurement of hemodynamics during postural changes using a new wearable cephalic laser blood flowmeter. Circ J 2009; 73: 1950-1955.

7. Iadecola C. Neurovascular regulation in the normal brain and in Alzheimer's disease. Nat Rev Neurosci 2004; 5: 347-360.

8. de la Torre JC. Alzheimer disease as a vascular disorder: Nosological evidence. Stroke 2002; 33: 1152-1162.

9. Edvinsson L, MacKenzie ET. General and comparative anatomy of the cerebral circulation. In: Edvinsson L, Krause DN, editors. Cerebral blood flow and metabolism. New York: Lippincott Williams and Wilkins, 2002; 3-29.

10. Iadecola C. Neurogenic control of the cerebral microcirculation: Is dopamine minding the store? Nat Neurosci 1998; 1: 263-265.

11. Cohen Z, Bonvento G, Lacombe P, Hamel E. Serotonin in the regulation of brain microcirculation. Prog Neurobiol 1996; 50: $335-362$.

12. Mulligan SJ, MacVicar BA. Calcium transients in astrocyte endfeet cause cerebrovascular constrictions. Nature 2004; 431: $195-$ 199.

13. Filosa JA, Bonev AD, Nelson MT. Calcium dynamics in cortical astrocytes and arterioles during neurovascular coupling. Circ Res 2004; 95: e73-e81.

14. Zonta M, Angulo MC, Gobbo S, Rosengarten B, Hossmann KA, Pozzan T, et al. Neuron-to-astrocyte signaling is central to the dynamic control of brain microcirculation. Nat Neurosci 2003; 6: $43-50$.
15. Simard M, Arcuino G, Takano T, Liu QS, Nedergaard M. Signaling at the gliovascular interface. J Neurosci 2003; 23: 92549262.

16. Araque A, Parpura V, Sanzgiri RP, Haydon PG. Tripartite synapses: Glia, the unacknowledged partner. Trends Neurosci 1999; 22: $208-215$.

17. Kacem K, Lacombe P, Seylaz J, Bonvento G. Structural organization of the perivascular astrocyte endfeet and their relationship with the endothelial glucose transporter: A confocal microscopy study. Glia 1998; 23: 1-10.

18. Edvinsson L, Hamel E. Perivascular nerves in brain vessels. In: Edvinsson L, Krause DN, editors. Cerebral blood flow and metabolism. New York: Lippincott Williams and Wilkins, 2002; 4367.

19. Diamond JS. Deriving the glutamate clearance time course from transporter currents in CA1 hippocampal astrocytes: Transmitter uptake gets faster during development. J Neurosci 2005; 25: 29062916.

20. Nagelhus EA, Mathiisen TM, Ottersen OP. Aquaporin-4 in the central nervous system: Cellular and subcellular distribution and coexpression with KIR4.1. Neuroscience 2004; 129: 905-913.

21. Kofuji P, Newman EA. Potassium buffering in the central nervous system. Neuroscience 2004; 129: 1045-1056.

22. Fellin T, Carmignoto G. Neurone-to-astrocyte signalling in the brain represents a distinct multifunctional unit. J Physiol 2004; 559: $3-15$

23. Porter JT, McCarthy KD. Hippocampal astrocytes in situ respond to glutamate released from synaptic terminals. J Neurosci 1996; 16: $5073-5081$.

24. Duffy S, MacVicar BA. Adrenergic calcium signaling in astrocyte networks within the hippocampal slice. J Neurosci 1995; 15: $5535-5550$.

25. Cornell-Bell AH, Finkbeiner SM, Cooper MS, Smith SJ. Glutamate induces calcium waves in cultured astrocytes: Long-range glial signaling. Science 1990; 247: 470-473.

26. Parri HR, Crunelli V. The role of $\mathrm{Ca} 2+$ in the generation of spontaneous astrocytic Ca2+ oscillations. Neuroscience 2003; 120: 979-992.

27. Golovina VA, Blaustein MP. Unloading and refilling of two classes of spatially resolved endoplasmic reticulum $\mathrm{Ca}(2+)$ stores in astrocytes. Glia 2000; 31: 15-28.

28. Harder DR, Alkayed NJ, Lange AR, Gebremedhin D, Roman RJ. Functional hyperemia in the brain: Hypothesis for astrocytederived vasodilator metabolites. Stroke 1998; 29: 229-234.

29. Harder DR, Zhang C, Gebremedhin D. Astrocytes function in matching blood flow to metabolic activity. News Physiol Sci 2002; 17: $27-31$.

30. Harder DR, Roman RJ, Gebremedhin D, Birks EK, Lange AR. A common pathway for regulation of nutritive blood flow to the brain: Arterial muscle membrane potential and cytochrome P450 metabolites. Acta Physiol Scand 1998; 164: 527-532.

31. Amruthesh SC, Boerschel MF, McKinney JS, Willoughby KA, Ellis EF. Metabolism of arachidonic acid to epoxyeicosatrienoic acids, hydroxyeicosatetraenoic acids, and prostaglandins in cultured rat hippocampal astrocytes. J Neurochem 1993; 61: 150159.

32. Alkayed NJ, Narayanan J, Gebremedhin D, Medhora M, Roman RJ, Harder DR. Molecular characterization of an arachidonic acid epoxygenase in rat brain astrocytes. Stroke 1996; 27: 971-979.

33. Gebremedhin D, Ma YH, Falck JR, Roman RJ, VanRollins M, Harder DR. Mechanism of action of cerebral epoxyeicosatrienoic acids on cerebral arterial smooth muscle. Am J Physiol 1992; 263: H519-H525.

34. Roman RJ. P-450 metabolites of arachidonic acid in the control of cardiovascular function. Physiol Rev 2002; 82: 131-185.

35. Lovick TA, Brown LA, Key BJ. Neuronal activity-related coupling in cortical arterioles: Involvement of astrocyte-derived factors. Exp Physiol 2005; 90: $131-140$

36. Zonta M, Sebelin A, Gobbo S, Fellin T, Pozzan T, Carmignoto G. Glutamate-mediated cytosolic calcium oscillations regulate a pulsatile prostaglandin release from cultured rat astrocytes. $J$ Physiol 2003; 553: 407-414.

37. Brayden JE, Nelson MT. Regulation of arterial tone by activation of calcium-dependent potassium channels. Science 1992; 256: $532-535$

38. Miyata N, Taniguchi K, Seki T, Ishimoto T, Sato-Watanabe M, Yasuda Y, et al. HET0016, a potent and selective inhibitor of 20HETE synthesizing enzyme. Br J Pharmacol 2001; 133: 325-329.

39. Dunn KM, Renic M, Flasch AK, Harder DR, Falck J, Roman RJ. Elevated production of 20-HETE in the cerebral vasculature con- 
tributes to severity of ischemic stroke and oxidative stress in spontaneously hypertensive rats. Am J Physiol Heart Circ Physiol 2008; 295: $\mathrm{H} 2455-\mathrm{H} 2465$.

40. Knot HJ, Zimmermann PA, Nelson MT. Extracellular K(+)-induced hyperpolarizations and dilatations of rat coronary and cerebral arteries involve inward rectifier K(+) channels. J Physiol 1996; 492(Pt 2): 419-430.

41. Newman EA. Regional specialization of retinal glial cell membrane. Nature 1984; 309: 155-157.

42. Gebremedhin D, Yamaura K, Zhang C, Bylund J, Koehler RC, Harder DR. Metabotropic glutamate receptor activation enhances the activities of two types of $\mathrm{Ca} 2+$-activated $\mathrm{k}+$ channels in rat hippocampal astrocytes. J Neurosci 2003; 23: 1678-1687.

43. Price DL, Ludwig JW, Mi H, Schwarz TL, Ellisman MH. Distribution of rSlo $\mathrm{Ca} 2+$-activated $\mathrm{K}+$ channels in rat astrocyte perivascular endfeet. Brain Res 2002; 956: 183-193.

44. Filosa JA, Bonev AD, Straub SV, Meredith AL, Wilkerson MK, Aldrich RW, et al. Local potassium signaling couples neuronal activity to vasodilation in the brain. Nat Neurosci 2006; 9: 1397 1403.

45. Nelson MT, Patlak JB, Worley JF, Standen NB. Calcium channels, potassium channels, and voltage dependence of arterial smooth muscle tone. Am J Physiol 1990; 259: C3-C18.

46. Hayashi T, Ichikawa M, Iwata A, Nakata T, Lim YJ, Mishima M. Intracoronary nicorandil relieves multiple coronary vasospasm with hemodynamic collapse. Circ J 2008; 72: 327-330.

47. Rubart M, Patlak JB, Nelson MT. Ca2+ currents in cerebral artery smooth muscle cells of rat at physiological $\mathrm{Ca} 2+$ concentrations. J Gen Physiol 1996; 107: 459-472.

48. Knot HJ, Nelson MT. Regulation of arterial diameter and wall $[\mathrm{Ca} 2+]$ in cerebral arteries of rat by membrane potential and intravascular pressure. J Physiol 1998; 508(Pt 1): 199-209.

49. Nelson MT, Quayle JM. Physiological roles and properties of potassium channels in arterial smooth muscle. Am J Physiol 1995; 268: C799-C822.

50. Yang Y, Murphy TV, Ella SR, Grayson TH, Haddock R, Hwang YT, et al. Heterogeneity in function of small artery smooth muscle BKCa: Involvement of the beta1-subunit. J Physiol 2009; 587: 3025-3044.

51. Girouard H, Bonev AD, Hannah RM, Meredith A, Aldrich RW, Nelson MT. Astrocytic endfoot $\mathrm{Ca} 2+$ and BK channels determine both arteriolar dilation and constriction. Proc Natl Acad Sci USA 2010; 107: 3811-3816.

52. Li A, Xi Q, Umstot ES, Bellner L, Schwartzman ML, Jaggar JH, et al. Astrocyte-derived $\mathrm{CO}$ is a diffusible messenger that mediates glutamate-induced cerebral arteriolar dilation by activating smooth muscle Cell KCa channels. Circ Res 2008; 102: 234-241.

53. Straub SV, Girouard H, Doetsch PE, Hannah RM, Wilkerson MK, Nelson MT. Regulation of intracerebral arteriolar tone by K(v) channels: Effects of glucose and PKC. Am J Physiol Cell Physiol 2009; 297: C788-C796.

54. Kinoshita H, Nakahata K, Dojo M, Kimoto Y, Hatano Y. Lidocaine impairs vasodilation mediated by adenosine triphosphatesensitive $\mathrm{K}+$ channels but not by inward rectifier $\mathrm{K}+$ channels in rat cerebral microvessels. Anesth Analg 2004; 99: 904-909, table of contents.

55. Zaritsky JJ, Eckman DM, Wellman GC, Nelson MT, Schwarz TL. Targeted disruption of Kir2.1 and Kir2.2 genes reveals the essential role of the inwardly rectifying $\mathrm{K}(+)$ current in $\mathrm{K}(+)$-mediated vasodilation. Circ Res 2000; 87: 160-166.

56. Bradley KK, Jaggar JH, Bonev AD, Heppner TJ, Flynn ER, Nelson MT, et al. Kir2.1 encodes the inward rectifier potassium channel in rat arterial smooth muscle cells. J Physiol 1999; $\mathbf{5 1 5}(\mathrm{Pt}$ 3): $639-651$.

57. Ficker E, Taglialatela M, Wible BA, Henley CM, Brown AM. Spermine and spermidine as gating molecules for inward rectifier K+ channels. Science 1994; 266: $1068-1072$.

58. Lopatin AN, Makhina EN, Nichols CG. Potassium channel block by cytoplasmic polyamines as the mechanism of intrinsic rectification. Nature 1994; 372: 366-369.

59. Lopatin AN, Makhina EN, Nichols CG. The mechanism of inward rectification of potassium channels: "Long-pore plugging" by cytoplasmic polyamines. J Gen Physiol 1995; 106: 923-955.

60. Quayle JM, Nelson MT, Standen NB. ATP-sensitive and inwardly rectifying potassium channels in smooth muscle. Physiol Rev 1997; 77: $1165-1232$

61. Quayle JM, McCarron JG, Brayden JE, Nelson MT. Inward rectifier $\mathrm{K}+$ currents in smooth muscle cells from rat resistance-sized cerebral arteries. Am J Physiol 1993; 265: C1363-C1370.

62. Knot HJ, Nelson MT. Regulation of membrane potential and diameter by voltage-dependent $\mathrm{K}+$ channels in rabbit myogenic cerebral arteries. Am J Physiol 1995; 269: H348-H355.

63. Ledoux J, Werner ME, Brayden JE, Nelson MT. Calcium-activated potassium channels and the regulation of vascular tone. Physiology (Bethesda) 2006; 21: 69-78.

64. Knaus HG, Eberhart A, Glossmann H, Munujos P, Kaczorowski GJ, Garcia ML. Pharmacology and structure of high conductance calcium-activated potassium channels. Cell Signal 1994; 6: 861 870.

65. Tanaka Y, Meera P, Song M, Knaus HG, Toro L. Molecular constituents of maxi KCa channels in human coronary smooth muscle: Predominant alpha + beta subunit complexes. J Physiol 1997; 502(Pt 3): 545-557.

66. Brenner R, Perez GJ, Bonev AD, Eckman DM, Kosek JC, Wiler $\mathrm{SW}$, et al. Vasoregulation by the beta1 subunit of the calciumactivated potassium channel. Nature 2000; 407: 870-876.

67. McGahon MK, Dash DP, Arora A, Wall N, Dawicki J, Simpson DA, et al. Diabetes downregulates large-conductance Ca2+-activated potassium beta 1 channel subunit in retinal arteriolar smooth muscle. Circ Res 2007; 100: 703-711.

68. Amberg GC, Bonev AD, Rossow CF, Nelson MT, Santana LF. Modulation of the molecular composition of large conductance, $\mathrm{Ca}(2+)$ activated $\mathrm{K}(+)$ channels in vascular smooth muscle during hypertension. J Clin Invest 2003; 112: 717-724.

69. Amberg GC, Santana LF. Downregulation of the BK channel beta1 subunit in genetic hypertension. Circ Res 2003; 93: $965-$ 971.

70. Chang T, Wu L, Wang R. Altered expression of BK channel beta 1 subunit in vascular tissues from spontaneously hypertensive rats. Am J Hypertens 2006; 19: 678-685.

71. Rusch NJ. BK channels in cardiovascular disease: A complex story of channel dysregulation. Am J Physiol Heart Circ Physiol 2009; 297: H1580-H1582.

72. Fernandez-Fernandez JM, Tomas M, Vazquez E, Orio P, Latorre $\mathrm{R}$, Senti $\mathrm{M}$, et al. Gain-of-function mutation in the KCNMB1 potassium channel subunit is associated with low prevalence of diastolic hypertension. J Clin Invest 2004; 113: 1032-1039.

73. Senti M, Fernandez-Fernandez JM, Tomas M, Vazquez E, Elosua $\mathrm{R}$, Marrugat J, et al. Protective effect of the KCNMB1 E65K genetic polymorphism against diastolic hypertension in aging women and its relevance to cardiovascular risk. Circ Res 2005; 97: $1360-1365$.

74. Galvez A, Gimenez-Gallego G, Reuben JP, Roy-Contancin L, Feigenbaum P, Kaczorowski GJ, et al. Purification and characterization of a unique, potent, peptidyl probe for the high conductance calcium-activated potassium channel from venom of the scorpion Buthus tamulus. J Biol Chem 1990; 265: 11083-11090.

75. Gribkoff VK, Starrett JE Jr, Dworetzky SI. The pharmacology and molecular biology of large-conductance calcium-activated (BK) potassium channels. Adv Pharmacol 1997; 37: 319-348.

76. Li G, Cheung DW. Effects of paxilline on $\mathrm{K}+$ channels in rat mesenteric arterial cells. Eur J Pharmacol 1999; 372: 103-107.

77. Butera JA, Jenkins DJ, Lennox JR, Sheldon JH, Norton NW, Warga D, et al. Synthesis and bladder smooth muscle relaxing properties of substituted 3-amino-4-aryl-(and aralkyl-)cyclobut3-ene-1,2-diones. Bioorg Med Chem Lett 2005; 15: 2495-2501.

78. Hewawasam P, Gribkoff VK, Pendri Y, Dworetzky SI, Meanwell NA, Martinez E, et al. The synthesis and characterization of BMS204352 (MaxiPost) and related 3-fluorooxindoles as openers of maxi-K potassium channels. Bioorg Med Chem Lett 2002; 12: $1023-1026$.

79. Siemer C, Bushfield M, Newgreen D, Grissmer S. Effects of NS1608 on MaxiK channels in smooth muscle cells from urinary bladder. J Membr Biol 2000; 173: 57-66.

80. Layne JJ, Nausch B, Olesen SP, Nelson MT. BK channel activation by NS11021 decreases excitability and contractility of urinary bladder smooth muscle. Am J Physiol Regul Integr Comp Physiol 2010; 298: R378-R384.

81. Robertson BE, Schubert R, Hescheler J, Nelson MT. cGMPdependent protein kinase activates Ca-activated $\mathrm{K}$ channels in cerebral artery smooth muscle cells. Am J Physiol 1993; 265: C299-C303.

82. Schubert R, Nelson MT. Protein kinases: Tuners of the BKCa channel in smooth muscle. Trends Pharmacol Sci 2001; 22: $505-512$

83. Lange A, Gebremedhin D, Narayanan J, Harder D. 20-Hydroxyeicosatetraenoic acid-induced vasoconstriction and inhibition of potassium current in cerebral vascular smooth muscle is dependent on activation of protein kinase C. J Biol Chem 1997; 272: $27345-27352$. 
84. Sun CW, Falck JR, Harder DR, Roman RJ. Role of tyrosine kinase and PKC in the vasoconstrictor response to 20-HETE in renal arterioles. Hypertension 1999; 33: 414-418.

85. Obara K, Koide M, Nakayama K. 20-Hydroxyeicosatetraenoic acid potentiates stretch-induced contraction of canine basilar artery via PKC alpha-mediated inhibition of KCa channel. $\mathrm{Br} J$ Pharmacol 2002; 137: 1362-1370.

86. Yang W, Gauthier KM, Reddy LM, Sangras B, Sharma KK, Nithipatikom K, et al. Stable 5,6-epoxyeicosatrienoic acid analog relaxes coronary arteries through potassium channel activation. Hypertension 2005; 45: 681-686.

87. Larsen BT, Miura H, Hatoum OA, Campbell WB, Hammock BD, Zeldin DC, et al. Epoxyeicosatrienoic and dihydroxyeicosatrienoic acids dilate human coronary arterioles via BK(Ca) channels: Implications for soluble epoxide hydrolase inhibition. Am J Physiol Heart Circ Physiol 2006; 290: H491 - H499.

88. Cheong A, Quinn K, Dedman AM, Beech DJ. Activation thresholds of $\mathrm{K}(\mathrm{V})$, BK and $\mathrm{Cl}(\mathrm{Ca})$ channels in smooth muscle cells in pial precapillary arterioles. J Vasc Res 2002; 39: 122-130.

89. Cipolla MJ, Smith J, Kohlmeyer MM, Godfrey JA. SKCa and IKCa Channels, myogenic tone, and vasodilator responses in middle cerebral arteries and parenchymal arterioles: Effect of ischemia and reperfusion. Stroke 2009; 40: 1451-1457.

90. Kanu A, Leffler CW. Carbon monoxide and $\mathrm{Ca} 2+$-activated $\mathrm{K}+$ channels in cerebral arteriolar responses to glutamate and hypoxia in newborn pigs. Am J Physiol Heart Circ Physiol 2007; 293: $\mathrm{H} 3193-\mathrm{H} 3200$.

91. Albarwani S, Nemetz LT, Madden JA, Tobin AA, England SK, Pratt PF, et al. Voltage-gated $\mathrm{K}+$ channels in rat small cerebral arteries: Molecular identity of the functional channels. $J$ Physiol 2003; 551: 751-763.

92. Chen TT, Luykenaar KD, Walsh EJ, Walsh MP, Cole WC. Key role of Kv1 channels in vasoregulation. Circ Res 2006; 99: 53 60 .

93. Rainbow RD, Norman RI, Everitt DE, Brignell JL, Davies NW, Standen NB. Endothelin-I and angiotensin II inhibit arterial voltage-gated $\mathrm{K}+$ channels through different protein kinase $\mathrm{C}$ isoenzymes. Cardiovasc Res 2009; 83: 493-500.

94. Standen NB, Quayle JM. K+ channel modulation in arterial smooth muscle. Acta Physiol Scand 1998; 164: 549-557.

95. Cole WC, Clement-Chomienne O, Aiello EA. Regulation of 4aminopyridine-sensitive, delayed rectifier $\mathrm{K}+$ channels in vascular smooth muscle by phosphorylation. Biochem Cell Biol 1996; 74: $439-447$.

96. Rainbow RD, Hardy ME, Standen NB, Davies NW. Glucose reduces endothelin inhibition of voltage-gated potassium channels in rat arterial smooth muscle cells. J Physiol 2006; 575: $833-844$.

97. Seino S. ATP-sensitive potassium channels: A model of heteromultimeric potassium channel/receptor assemblies. Annu Rev Physiol 1999; 61: 337-362.

98. Watanabe N, Akasaka T, Fujimoto K, Kajita T, Shigeto F, Neishi $\mathrm{Y}$, et al. Effect of nicorandil, a $\mathrm{K}^{+}{ }_{\mathrm{ATP}}$-channel opener, on coronary capillary architecture and volume after early myocardial ischemiareperfusion: A 3-dimensional confocal laser microscopic study. Circ J 2004; 68: 1210-1214.

99. Nakahata K, Kinoshita H, Hirano Y, Kimoto Y, Iranami H, Hatano Y. Mild hypercapnia induces vasodilation via adenosine triphosphate-sensitive $\mathrm{K}+$ channels in parenchymal microvessels of the rat cerebral cortex. Anesthesiology 2003; 99: 1333-1339.

100. Kajita Y, Takayasu M, Yoshida J, Dietrich HH, Dacey RG Jr. Vasodilatory effect of basic fibroblast growth factor in isolated rat cerebral arterioles: Mechanisms involving nitric oxide and membrane hyperpolarization. Neurol Med Chir (Tokyo) 2001; 41: 177-185; discussion 185-176.

101. Standen NB, Quayle JM, Davies NW, Brayden JE, Huang Y, Nelson MT. Hyperpolarizing vasodilators activate ATP-sensitive $\mathrm{K}+$ channels in arterial smooth muscle. Science 1989; 245: $177-$ 180 .

102. Nelson MT, Huang Y, Brayden JE, Hescheler J, Standen NB. Arterial dilations in response to calcitonin gene-related peptide involve activation of K+ channels. Nature 1990; 344: 770-773.

103. Niwa K, Araki E, Morham SG, Ross ME, Iadecola C. Cyclooxygenase-2 contributes to functional hyperemia in whisker-barrel cortex. J Neurosci 2000; 20: 763-770.

104. Takano T, Tian GF, Peng W, Lou N, Libionka W, Han X, et al. Astrocyte-mediated control of cerebral blood flow. Nat Neurosci 2006; 9: 260-267.
105. Petzold GC, Albeanu DF, Sato TF, Murthy VN. Coupling of neural activity to blood flow in olfactory glomeruli is mediated by astrocytic pathways. Neuron 2008; 58: 897-910.

106. Zhang Y, Pertens E, Janssen LJ. 8-isoprostaglandin E(2) activates $\mathrm{Ca}(2+)$-dependent $\mathrm{K}(+)$ current via cyclic AMP signaling pathway in murine renal artery. Eur J Pharmacol 2005; 520: 22 -28.

107. Wahl M, Schilling L, Whalley ET. Cerebrovascular effects of prostanoids. In-situ studies in pial arteries of the cat. Naunyn Schmiedebergs Arch Pharmacol 1989; 340: 314-320.

108. Davis RJ, Murdoch CE, Ali M, Purbrick S, Ravid R, Baxter GS, et al. EP4 prostanoid receptor-mediated vasodilatation of human middle cerebral arteries. Br J Pharmacol 2004; 141: 580-585.

109. Kimura M, Dietrich HH, Dacey RG Jr. Nitric oxide regulates cerebral arteriolar tone in rats. Stroke 1994; 25: 2227-2233; discussion 2233-2224.

110. van Rodijnen WF, Korstjens IJ, Legerstee N, Ter Wee PM, Tangelder GJ. Direct vasoconstrictor effect of prostaglandin E2 on renal interlobular arteries: Role of the EP3 receptor. Am J Physiol Renal Physiol 2007; 292: F1094-F1101.

111. Janssen LJ, Tazzeo T. Involvement of TP and EP3 receptors in vasoconstrictor responses to isoprostanes in pulmonary vasculature. J Pharmacol Exp Ther 2002; 301: 1060-1066.

112. Jadhav V, Jabre A, Lin SZ, Lee TJ. EP1- and EP3-receptors mediate prostaglandin E2-induced constriction of porcine large cerebral arteries. J Cereb Blood Flow Metab 2004; 24: 1305-1316.

113. Metea MR, Newman EA. Glial cells dilate and constrict blood vessels: A mechanism of neurovascular coupling. J Neurosci 2006; 26: $2862-2870$.

114. Metea MR, Newman EA. Signalling within the neurovascular unit in the mammalian retina. Exp Physiol 2007; 92: 635-640.

115. Peng X, Carhuapoma JR, Bhardwaj A, Alkayed NJ, Falck JR, Harder DR, et al. Suppression of cortical functional hyperemia to vibrissal stimulation in the rat by epoxygenase inhibitors. Am J Physiol Heart Circ Physiol 2002; 283: H2029-H2037.

116. Liu X, Li C, Falck JR, Roman RJ, Harder DR, Koehler RC. Interaction of nitric oxide, 20-HETE, and EETs during functional hyperemia in whisker barrel cortex. Am J Physiol Heart Circ Physiol 2008; 295: H619-H631.

117. Leffler CW, Fedinec AL. Newborn piglet cerebral microvascular responses to epoxyeicosatrienoic acids. Am J Physiol 1997; 273: $\mathrm{H} 333-\mathrm{H} 338$

118. Ellis EF, Police RJ, Yancey L, McKinney JS, Amruthesh SC. Dilation of cerebral arterioles by cytochrome P-450 metabolites of arachidonic acid. Am J Physiol 1990; 259: H1171 - H1177.

119. Hercule HC, Salanova B, Essin K, Honeck H, Falck JR, Sausbier $\mathrm{M}$, et al. The vasodilator 17,18-epoxyeicosatetraenoic acid targets the pore-forming BK alpha channel subunit in rodents. Exp Physiol 2007; 92: 1067-1076.

120. Iliff JJ, Wang R, Zeldin DC, Alkayed NJ. Epoxyeicosanoids as mediators of neurogenic vasodilation in cerebral vessels. Am J Physiol Heart Circ Physiol 2009; 296: H1352-H1363.

121. Earley S, Heppner TJ, Nelson MT, Brayden JE. TRPV4 forms a novel $\mathrm{Ca} 2+$ signaling complex with ryanodine receptors and BKCa channels. Circ Res 2005; 97: 1270-1279.

122. Cambj-Sapunar L, Yu M, Harder DR, Roman RJ. Contribution of 5-hydroxytryptamine1B receptors and 20-hydroxyeiscosatetraenoic acid to fall in cerebral blood flow after subarachnoid hemorrhage. Stroke 2003; 34: 1269-1275

123. Yu M, Cambj-Sapunar L, Kehl F, Maier KG, Takeuchi K, Miyata $\mathrm{N}$, et al. Effects of a 20-HETE antagonist and agonists on cerebral vascular tone. Eur J Pharmacol 2004; 486: 297-306.

124. Harder DR, Gebremedhin D, Narayanan J, Jefcoat C, Falck JR, Campbell WB, et al. Formation and action of a P-450 4A metabolite of arachidonic acid in cat cerebral microvessels. Am J Physiol 1994; 266: H2098-H2107.

125. Horiuchi T, Dietrich HH, Hongo K, Dacey RG Jr. Mechanism of extracellular $\mathrm{K}+$-induced local and conducted responses in cerebral penetrating arterioles. Stroke 2002; 33: 2692-2699.

126. Armstead WM, Mirro R, Busija DW, Leffler CW. Vascular responses to vasopressin are tone-dependent in the cerebral circulation of the newborn pig. Circ Res 1989; 64: 136-144.

127. Rosenblum WI, Nelson GH. Tone regulates opposing endothelium-dependent and -independent forces: Resistance brain vessels in vivo. Am J Physiol 1990; 259: H243-H247.

128. Blanco VM, Stern JE, Filosa JA. Tone-dependent vascular responses to astrocyte-derived signals. Am J Physiol Heart Circ Physiol 2008; 294: H2855-H2863. 